Edited by Allan Beveridge, Femi Oyebode and Rosalind Ramsay

\section{Forensic Mental Health} concepts, systems, and practice

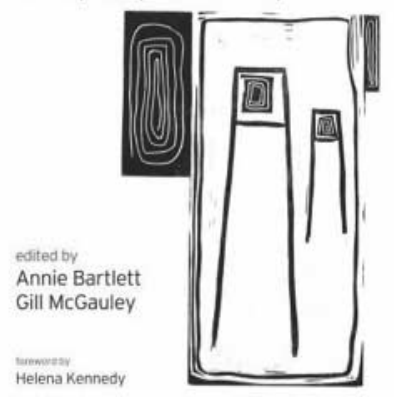

\section{Forensic Mental Health:} Concepts, Systems, and Practice

Edited by Annie Bartlett \& Gill McGauley.

Oxford University Press. 2009 £34.95 (pb). 448pp. ISBN: 9780198566854

New books do not emerge frequently in the field of what has come to be known as forensic mental health. I approached this one with some uncertainty in the light of its seemingly rather expansive subtitle. I need not have worried. Indeed, I should have known better given the editors and contributors (the foreword is by Baroness Helena Kennedy). Do not be taken in. The content is much wider and the book is both fresh and refreshing. It needs to be explored actively, otherwise one might miss something.

Reviews that simply list content can be dull. However, in this case it is important to do just that to describe at least some of the range of material covered. The book has six sections: Violence and Dangerousness, Forensic Psychotherapy, The Law, Ethics, Social Policy and International Perspectives. The content is strong throughout, particularly in relation to social, cultural and gender issues in the first section, introduced through a discussion of the medical model, anti-psychiatry and psychiatry as an institution. Someone with little or no knowledge of, or prior exposure to, the field could start right here. The same is true of the chapters on forensic psychotherapy and ethics, while retaining the sophistication that one would expect considering their authors.

I would venture to suggest also that anyone contemplating research into violence, even on a modest scale, should read at least the two chapters on criminological approaches to violence and its relationship with mental disorder. The section on the law is succinct and avoids the tendency to just catalogue sections of the relevant Acts. It gives clear guidance to those coming newly to the courts as well as offering insights to the more experienced. Again, the social policy chapters, centred on the development, in its widest sense, and delivery of services, describe, and perhaps more importantly reflect upon, the ever-changing landscape. Even the international perspectives, which can, when included, seem to be an afterthought, here are relevant, helpful and interesting to read. The concept of the 'sliding scale' of responsibility, or rather lack of it, and its origins, which may be considered in any case before the Dutch courts is fascinating. All chapters have stated aims, learning objectives and conclusions, and are well referenced so they meet the requirements of modern-day learners.

This is a book for Masters-level students or postgraduate trainees. It will also be of immense value to established

practitioners. For interested undergraduates from all the allied disciplines it will only serve to fuel their enthusiasm.

Martin Humphreys Senior Lecturer in Forensic Psychiatry, University of Birmingham, and Birmingham and Solihull Mental Health NHS Foundation Trust, Hillis Lodge, Hollymoor Way, Northfield, Birmingham B31 5HE, UK. Email: martin.humphreys@bsmhft.nhs.uk

doi: 10.1192/bjp.bp.110.084509

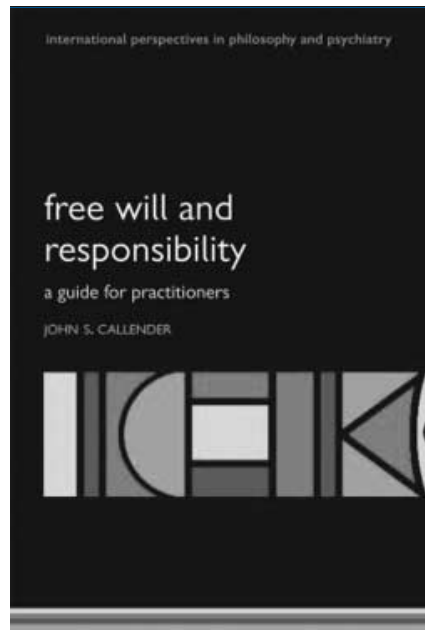

\section{Free will and} Responsibility: A Guide for Practitioners

International Perspectives in Philosophy and Psychiatry series By John S. Callender.

Oxford University Press. 2010

£39.95 (pb). 408pp.

ISBN: 9780199545551

This book is a real treat. John Callender offers an engaging and rigorous account of how science and morality meet, addressing important issues which should be thought about and discussed well beyond academic circles.

In the first part, 'Thinking about morality', Callender tackles the following questions: how did morality evolve? Which role do emotions play in moral decisions-making? On what grounds is punishment for wrongdoing justifiable? Many of the scientific studies that have made an impact on thinking about morality and moral responsibility are described, their results assessed, and their implications explored. For instance, Haidt's social intuitionism model and Libet's studies on the causal (in)efficacy of conscious decisions are discussed at length. The main theories in moral and political philosophy are presented fairly, compared and challenged on both conceptual and empirical grounds. That is why this is not just a great prelude to what comes next, but also a useful and comprehensive introduction to ethics in its own right.

In the second part of the book, 'Thinking about free will', the reader appreciates more of Callender's own original thesis that the philosophical and practical problem of free will and moral responsibility can be enlightened by considering the role of spontaneity and creativity in art. The initial sections are a good critical summary of the literature on the alleged conflict between determinism and free will, and the implications that different solutions to this conflict have for moral responsibility and for reward and punishment. The later sections are where the author develops his idea that art and morals overlap and that moral judgements have a lot in common with aesthetic judgements.

The third part, on clinical applications, helps the reader apply the previous discussion to concrete cases of normal and pathological 'lack of freedom'. One chapter is dedicated to psychopathic personality disorder, one to trauma and dissociation, and one to the several dimensions of psychotherapy. 